ARTICLE

DOI: $10.1038 / \mathrm{s} 41467-018-04571-4$

\title{
Upconversion nanocomposite for programming combination cancer therapy by precise control of microscopic temperature
}

\author{
Xingjun Zhu' ${ }^{1}$, Jiachang Li ${ }^{1}$, Xiaochen Qiu', Yi Liu', Wei Feng ${ }^{1} \&$ Fuyou Li ${ }^{1}$
}

Combinational administration of chemotherapy (CT) and photothermal therapy (PTT) has been widely used to treat cancer. However, the scheduling of CT and PTT and how it will affect the therapeutic efficacy has not been thoroughly investigated. The challenge is to realize the sequence control of these two therapeutic modes. Herein, we design a temperature sensitive upconversion nanocomposite for CT-PTT combination therapy. By monitoring the microscopic temperature of the nanocomposite with upconversion luminescence, photothermal effect can be adjusted to achieve thermally triggered combination therapy with a sequence of CT, followed by PTT. We find that CT administered before PTT results in better therapeutic effect than other administration sequences when the dosages of chemodrug and heat are kept at the same level. This work proposes a programmed method to arrange the process of combination cancer therapy, which takes full advantage of each therapeutic mode and contributes to the development of new cancer therapy strategies.

\footnotetext{
${ }^{1}$ Department of Chemistry \& Institutes of Biomedical Sciences \& State Key Laboratory of Molecular Engineering of Polymers, Fudan University, 220 Handan Road, Shanghai 200433, China. Correspondence and requests for materials should be addressed to W.F. (email: fengweifd@fudan.edu.cn)

or to F.Y.L. (email: fyli@fudan.edu.cn)
} 
C ombination cancer therapy uses more than one treatment mode to treat patients, which exhibit additive killing effect to cancer to reduce progressing or relapse ${ }^{1}$. Nanomaterials become powerful tools in cancer treatment ${ }^{2-6}$. The concept of combination therapy was adopted recently to develop new anticancer nanoagents ${ }^{7-9}$. Nanosystems with multiple treatment modes involving chemotherapy, radiotherapy, photothermal therapy, photodynamic therapy, etc., have been reported so far ${ }^{10-}$ 18. Among them, the combination of chemotherapy (CT) and photothermal therapy (PTT) is quite common, and in most reported works, these two treatment modes were initiated at the same time ${ }^{19-28}$. Typically, a chemodrug is loaded in thermalresponsive compound and integrated with photothermal agent to form a CT-PTT therapeutic nanocomposite ${ }^{21}$. In this way, drug release is activated by photothermal effect. Considering that photothermal effect is usually monitored by macroscopic device (thermometer or infrared camera), the overall temperature (defined as apparent temperature) has to be kept at a high level to ensure drug release, which causes simultaneous administration of chemodrug and heat without adequate schedule. However, as evidenced by a number of studies, the sequence of CT and PTT will determine the final therapeutic efficacy ${ }^{29-33}$. For example, giving chemodrug (doxorubicin) prior to thermal therapy results in better antitumor effect than simultaneous intake $29,31,34$. If the sequence of the treatment modes can be properly arranged and the therapeutic efficacy improves, drug dosages may be reduced, thereby resulting in lesser side effects ${ }^{29}, 32,34$. In our view, monitoring and controlling nanocomposite's temperature (defined as the eigen temperature) is the key to schedule the treatment modes in CT-PTT combination therapy. If eigen temperature can be precisely controlled to just initiate drug release without excessive heat leading to PTT, the separation of the two treatment modes will be realized.

To detect the eigen temperature of the nanocomposite, microscopic temperature sensing method is indispensable. Luminescent sensing technology emerges as a powerful tool for the detection of microscopic temperature, owing to its high sensitivity and the use of small size probes. To date, several types of optical temperature probes such as small molecular dyes, quantum dots, polymers, and lanthanide-doped upconversion nanophosphors (Ln-UCNPs) have been developed ${ }^{35-42}$. Thanks to the unique luminescence process of converting low-energy excitation into high-energy emission, Ln-UCNPs exhibit multiple merits for temperature sensing in physiological environment such as low detection limitations, absence of autofluorescence, and less photodamage ${ }^{43-55}$. Recently, Ln-UCNPs combined with photothermal agents were used to detect the eigen temperature during photothermal process with improved accuracy of $\mathrm{PTT}^{56}$.

Herein, a temperature responsive upconversion nanosystem (TR-UCNS), which contains photothermal agent (Octabutoxyphthalocyanine palladium (II), abbreviated as $\mathrm{PdPc}$ ) and thermal responsive drug release unit (1,2-dipalmitoyl-sn-glycero-3phosphocholine, abbreviated as DPPC), is built to achieve programmed CT-PTT combination cancer therapy. Photothermal effect of TR-UCNS is generated by $730 \mathrm{~nm}$ laser irradiation. Eigen temperature during photothermal process is interpreted by measuring the temperature sensitive upconversion luminescence (UCL) of $\mathrm{Er}^{3+}$ with the excitation of $980 \mathrm{~nm}$ laser. Power density of $730 \mathrm{~nm}$ laser, corresponding to photothermal effect, is tuned in light of UCL feedback to schedule CT and PTT sequentially (Fig. 1).

\section{Results}

Synthesis and characterizations of TR-UCNS. The synthesis of TR-UCNS was achieved by a stepwise method, which is shown in

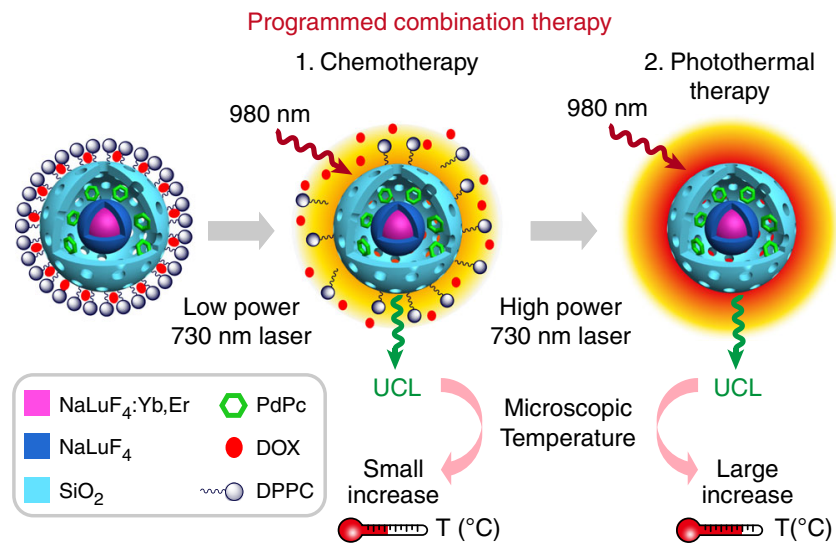

Fig. 1 Schematic diagram of programmed combination therapy. Temperature responsive upconversion nanosystem (TR-UCNS), which contained photothermal agent $(\mathrm{PdPc})$ and thermal responsive drug release unit (DPPC micelle), was built to perform programmed CT-PTT

combination cancer therapy. By monitoring the microscopic temperature of TR-UCNS with upconversion luminescence (UCL), the power density of photothermal excitation source ( $730 \mathrm{~nm}$ laser) can be tuned accurately to initiate thermal-controlled drug release and photothermal therapy stepwise, thereby programming the combination therapy. Programmed combination therapy showed better therapeutic effect at a lower drug dosage than conventional combination therapy, from which the treatment modes were initiated simultaneously

Supplementary Figure 1. Firstly, the lanthanide-doped upconversion nanoparticles $\left(\mathrm{NaLuF}_{4}: 20 \% \mathrm{Yb}, 2 \% \mathrm{Er}\right.$, abbreviated as UCNPs) are prepared by a solvothermal method ${ }^{57}$. As shown in the transmission electron microscopy (TEM) image, the morphology of UCNPs were spherical with a size of $13.4 \mathrm{~nm}$ in diameter (Fig. 2a). To enhance the upconversion luminescence (UCL), an undoped $\mathrm{NaLuF}_{4}$ layer was grown on the surface of UCNPs to form a core-shell structure $\left(\mathrm{NaLuF}_{4}: 20 \% \mathrm{Yb}, 2 \%\right.$ Er@NaLuF , here abbreviated as csUCNPs). The shape of csUCNPs remained spherical and the size increased to $20.5 \mathrm{~nm}$ in diameter (Fig. 2b). X-ray powder diffraction (XRD) patterns of csUCNPs indicated that both kinds of nanoparticles were the hexagonal phase of $\mathrm{NaLuF}_{4}$ (Supplementary Figure 2). The obtained csUCNPs with oleate as ligands can be easily dispersed in non-polar solvents. To realize the loading of photothermal agent and chemodrug, a porous-silica hollow shell was constructed outside csUCNPs through a hard template etching process. Here, a modified reverse microemulsion method was employed to form the etchable multilayered silica template ${ }^{58}$. Two kinds of organosilicone precursors, tetraethyl orthosilane (TEOS) and N-[3-(trimethoxysilyl)propyl]ethylenediamine (TSD), were used to deposit the silica layers with an adding sequence of TEOS, TEOS and TSD, and then TEOS. The silica layers coated on csUCNPs exhibited a whole thickness of $\sim 14 \mathrm{~nm}$ and kept the monodispersity of nanoparticles (Fig. 2c). As demonstrated in previous works ${ }^{58,59}$, the co-hydrolysis of TSD and TEOS makes the inner silica layer much looser than the outer layer, which is a hard template of the hollow cavity. With the treatment of $5 \%$ hydrofluoric acid solution, the template silica layer was etched and the outer silica layer was preserved to constitute the hollow shell. As shown in Fig. 2d, the yolk-shelllike nanoparticles $\left(\mathrm{NaLuF}_{4}: 20 \% \mathrm{Yb}, 2 \% \mathrm{Er} @ \mathrm{NaLuF}_{4} @ Y\right.$ Yolk-Shell $\mathrm{SiO}_{2}$, abbreviated as YSUCNP) were uniform in morphology with a diameter of $48.1 \mathrm{~nm}$ and the silica shell was $5.8 \mathrm{~nm}$ in thickness. Nitrogen adsorption-isotherm analysis confirmed the existence of a porous structure in YSUCNP (Supplementary Figure 3a), with a 
a

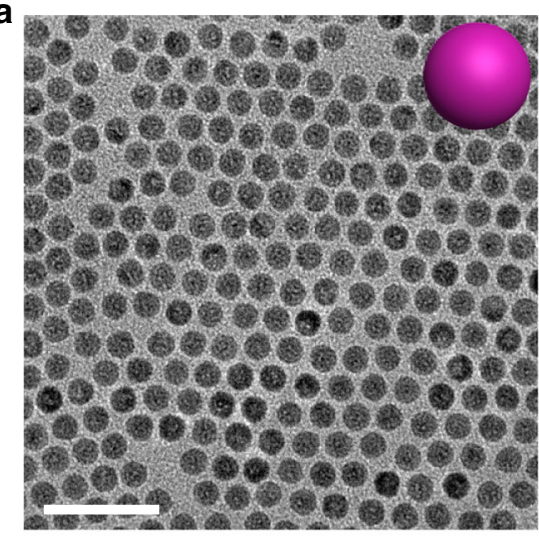

C

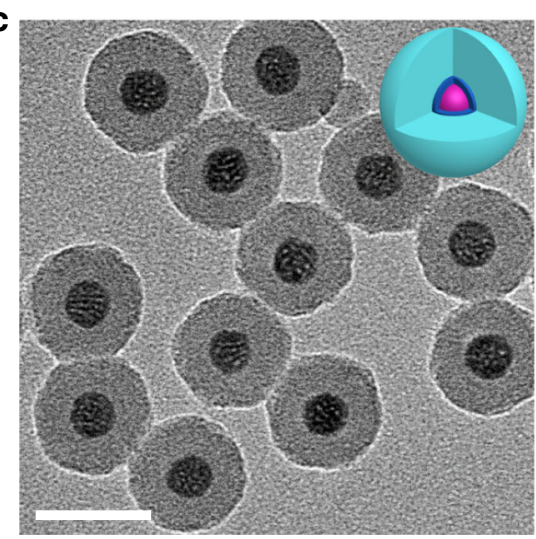

b

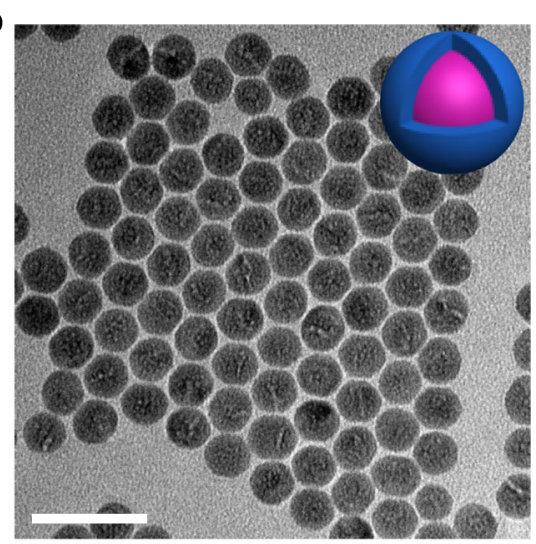

d

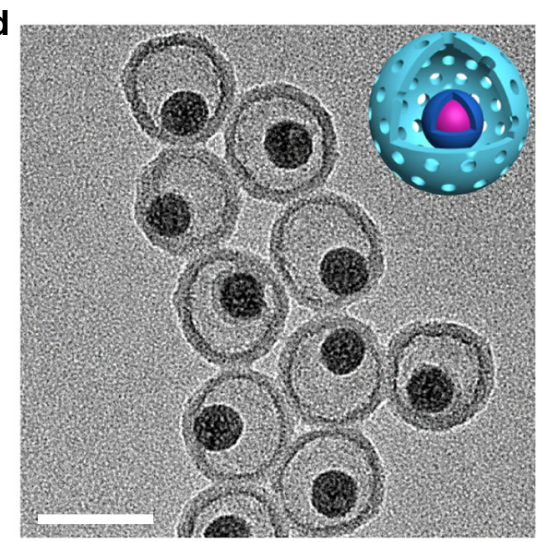

Fig. 2 Morphology characterization of the nanocomposite. TEM images of a NaLuF 4 :Yb,Er (UCNPs), b NaLuF $: Y_{4}, E_{0} @ N a L u F_{4}$ (csUCNPs), c NaLuF 4 :Yb,Er @NaLuF $4 \mathrm{SiO}_{2}$, and d NaLuF 4 :Yb,Er@NaLuF $4 @$ YYolk Shell-SiO 2 (YSUCNP). Scale bars were defined as 50 nm

pore volume of $0.296 \mathrm{~cm}^{3} \mathrm{~g}^{-1}$ and a Brunauer-Emmett-Teller (BET) surface area of $110 \mathrm{~m}^{2} \mathrm{~g}^{-1}$. The pore size distribution curve of YSUCNP had a sharp peak at $3.4 \mathrm{~nm}$, which indicated the mesoporosity of the silica shell (Supplementary Figure 3b).

The mesoporous silica shell and hollow cavity of YSUCNP make it possible to load the functional guest molecules. PdPc with strong absorption at near-infrared region was loaded in YSUCNP to endow the nanoparticles with photothermal conversion ability. Fourier-transform infrared spectroscopy revealed the appearance of stretching bands of $\mathrm{C}-\mathrm{H}$ bonds after $\mathrm{PdPc}$ loading (Supplementary Figure 3c). Energy-dispersive X-ray (EDX) mapping also confirmed the existence of palladium element in the nanoparticles (Supplementary Figure 4). This indicates the successful loading of PdPc in YSUCNP. To achieve the thermalresponsive chemodrug release, DPPC, of which the micelle can dissociate with the elevation of temperature, was selected as the vehicle of the chemodrug ${ }^{60-62}$. Doxorubicin (DOX), a commonly used chemodrug, was chosen as a typical example in this study ${ }^{29}$. The assembly of the drug release unit on the surface of YSUCNPPdPc to form YSUCNP-PdPc@DPPC-DOX (TR-UCNS) was performed according to a previously reported method ${ }^{63}$. TEM image of TR-UCNS showed a new coating layer outside the silica shell (Supplementary Figure 5). According to the data shown in Supplementary Figure $3 \mathrm{~d}$ and e, the molar of PdPc loaded in 20 $\mathrm{mg}$ YSUCNP is $1.28 \mu \mathrm{mol}\left(2 \mathrm{mg} \times 76.4 \% \times 1197.8 \mathrm{~g} \mathrm{~mol}^{-1}\right)$. The molar of $20 \mathrm{mg}$ YSUCNP is $0.31 \mathrm{nmol}$, so the number of PdPc in each YSUCNP nanoparticle is calculated by $1.28 \mu \mathrm{mol} / 0.31 \mathrm{nmol}$. Hence, there are $4129 \mathrm{PdPc}$ molecules in each YSUCNP particle. DOX laden on $10 \mathrm{mg}$ YSUCNP-PdPc (which contain $0.14 \mathrm{nmol}$ YSUCNP nanoparticles) is $0.115 \mu \mathrm{mol}(2.5 \mathrm{mM} \times 50 \mu \mathrm{l} \times 91.8 \%)$, so there are $\sim 821$ (calculated by $0.115 \mu \mathrm{mol} / 0.14 \mathrm{nmol}$ ) DOX molecules on each nanoparticle.
TR-UCNS exhibited a typical upconversion luminescence (UCL) emission of $\mathrm{Er}^{3+}$ ions under $980 \mathrm{~nm}$ laser excitation (Fig. 3a). Although the luminescence underwent slight suppression after the loading of PdPc and the adjunction of drug delivery unit, the overall intensity of TR-UCNS was still sufficient to carry out UCL-based temperature sensing and bioimaging. The existence of PdPc in TR-UCNS brought about a considerable absorption band centered at $\sim 750 \mathrm{~nm}$, which can be utilized to perform photothermal therapy under near-infrared light excitation (Fig. 3b). To evaluate the photothermal properties of TRUCNS, photothermal conversion efficiency was measured under the excitation of $730 \mathrm{~nm}$ laser. As shown in Supplementary Figure 6 , the final heat-generation efficiency $(\eta)$ was $54.2 \%$, which was higher than the gold nanostructures (e.g., $21 \%), \mathrm{Cu}_{9} \mathrm{~S}_{5}$ $(25.7 \%)$ and some organic materials ${ }^{56}$. Such high conversion efficiency is quite important, since the eigen temperature can be elevated to the level for drug release and PTT under more moderate laser irradiation.

Drug release by using eigen temperature. In the previous study, the eigen temperature of photothermal nanomaterials detected by UCL can be utilized to control the range of photothermal effect, thus improving the accuracy of PTT. Here we further applied the eigen temperature that just initiated the drug release without generating excessive amount of heat for restricting photothermal effect, thus separating CT and PTT in the combination therapy. In TR-UCNS, the upconversion core $\left(\mathrm{NaLuF}_{4}: 20 \% \mathrm{Yb}, 2 \% \mathrm{Er}\right)$ served as the reporter of eigen temperature during photothermal process. Since ${ }^{2} \mathrm{H}_{11 / 2} \rightarrow{ }^{4} \mathrm{I}_{15 / 2}$ and ${ }^{2} \mathrm{~S}_{3 / 2} \rightarrow{ }^{4} \mathrm{I}_{15 / 2}$ transitions (UCL emissions centered at 525 and $545 \mathrm{~nm}$, respectively) in $\mathrm{Er}^{3}$ ${ }^{+}$-doped upconversion system are in thermal equilibrium ruled 

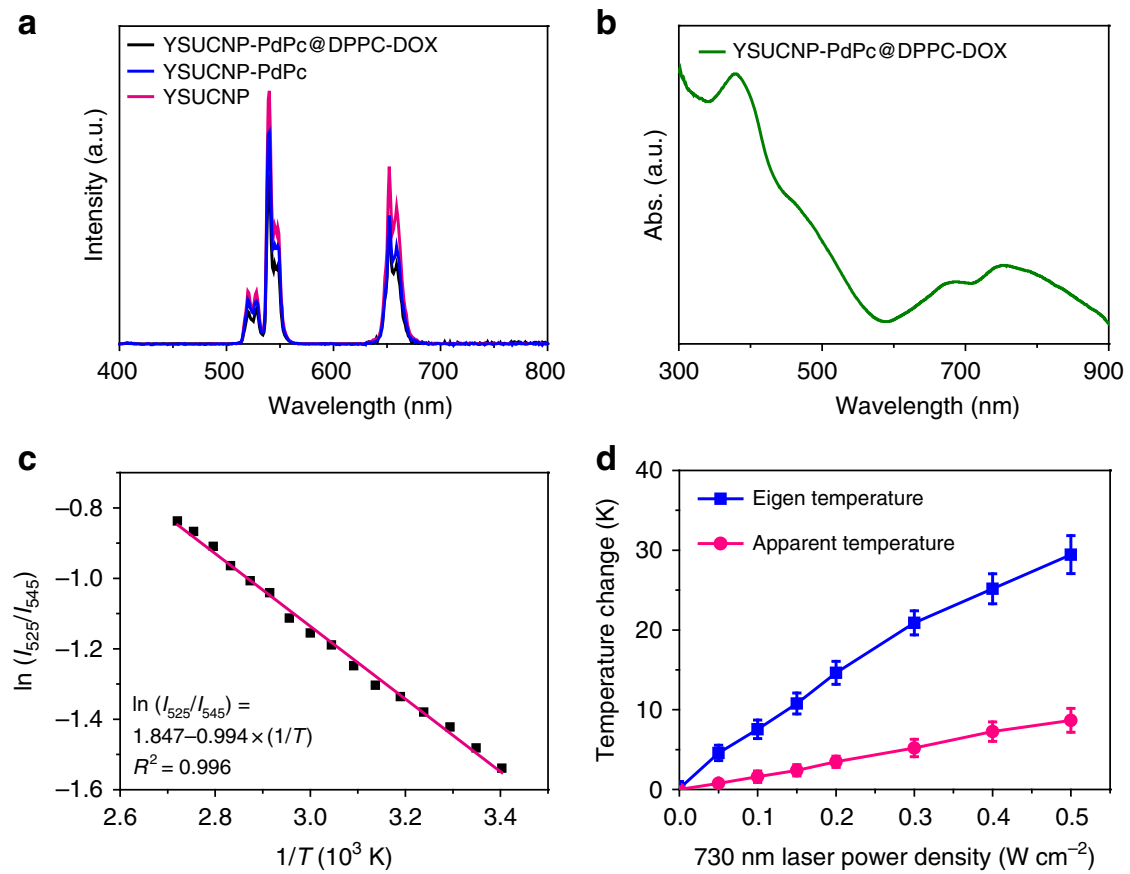

Fig. 3 Optical and temperature sensing properties of TR-UCNS. a Upconversion luminescence spectra of YSUCNP, YSUCNP-PdPc, and YSUCNPPdPc@DPPC-DOX (TR-UCNS) in the aqueous solution with the same concentration of $\mathrm{Er}^{3+}\left(2.5 \times 10^{-5} \mathrm{~mol}^{-1}\right)$. The excitation wavelength of upconversion luminescence is $980 \mathrm{~nm}$. b Absorption spectrum of TR-UCNS. c A plot of In $\left(I_{525} / I_{545}\right)$ versus $1 / T$ to calibrate the thermometric scale for TRUCNS. $I_{525}$ and $I_{545}$ indicate the intensities of UCL emission of the ${ }^{2} \mathrm{H}_{11 / 2} \rightarrow{ }^{4} \mathrm{I}_{15 / 2}$ and ${ }^{4} \mathrm{~S}_{3 / 2} \rightarrow{ }^{4} \mathrm{I}_{15 / 2}$ transitions, respectively. $\mathbf{d}$ Elevation of apparent temperature (A.T.) and eigen temperature (E.T.) of TR-UCNS $\left(0.5 \mathrm{mg} \mathrm{ml}^{-1}\right)$ in aqueous dispersion under irradiation with a $730 \mathrm{~nm}$ laser at various power densities. Average value of A.T. and E.T. under different time points were given based on three times measurements. Error bars were defined as s.d. ( $n=3$ )

by the Boltzmann factor, temperature can be reflected by the intensity ratio of the two emission bands ${ }^{45}, 56$. The relationship between temperature and UCL emission conforms to the following equation (Eq. 1):

$$
\left(I_{525}\right) /\left(I_{545}\right)=C \exp (-\Delta E / k T),
$$

where $I_{525}$ and $I_{545}$ are the integrated intensity of UCL emission derived from the ${ }^{2} \mathrm{H}_{11 / 2} \rightarrow{ }^{4} \mathrm{I}_{15 / 2}$ and ${ }^{2} \mathrm{~S}_{3 / 2} \rightarrow{ }^{4} \mathrm{I}_{15 / 2}$ transitions, respectively; $C$ is a constant determined by degeneracy, spontaneous emission rate, and photon energies of the emitting states in the host materials; $\Delta E$ is the energy gap separating the two excited states; $k$ is the Boltzmann constant; $T$ is temperature using the Kelvin scale.

Firstly, UCL spectra of TR-UCNS aqueous solution at variable temperatures were collected to obtain a calibration curve for optical temperature sensing. As shown in Fig. 3c, the dependence of $\ln$ $\left(I_{525}\right) /\left(I_{545}\right)$ on the inverse of temperature $(1 / T)$ followed a linear relationship, which could be fitted as $\ln \left(I_{525}\right) /\left(I_{545}\right)=1.847-994 \times$ $(1 / T)$ ( $T$ given in $\mathrm{K})$. Then, TR-UCNS solution at $37^{\circ} \mathrm{C}$ was irradiated by $730 \mathrm{~nm}$ laser with different power densities to generate photothermal effect. UCL emission intensities at each point were detected to investigate the eigen temperature during the photothermal process. With the elevation of laser power density, the eigen temperature and apparent temperature of TR-UCNS rose correspondingly (Fig. 3d). The eigen temperature had a much greater magnitude of increase than apparent temperature, which was consistent with the previous results. It is worth noting that the eigen temperature of TR-UCNS reached to $41.6^{\circ} \mathrm{C}$ (apparent temperature reached to $37.8^{\circ} \mathrm{C}$ ) when the power density of laser was at $50 \mathrm{~mW}$ $\mathrm{cm}^{-2}$ (Fig. 3d). As reported in the previous study, the assembly consisting of DPPC molecules would completely dissociate at this temperature. We also observed the phenomenon that DOX release underwent a sharp improvement by heating TR-UCNS with an external device to such temperature (Fig. 4a). Hence, the DOX release process under $730 \mathrm{~nm}$ laser irradiation at $50 \mathrm{~mW} \mathrm{~cm}^{-2}$ was further investigated to verify the feasibility of realizing drug release by using eigen temperature. As shown in Fig. 4 b, nearly $95 \%$ of DOX released from TR-UCNS within $10 \mathrm{~min}$ under laser irradiation. On the other hand, the release rate was only $10.6 \%$ if TR-UCNS was externally heated to the same apparent temperature $\left(37.8^{\circ} \mathrm{C}\right)$ with laser irradiation at $50 \mathrm{~mW} \mathrm{~cm}^{-2}$. These results indicate that eigen temperature plays a more direct role in drug release relying on photothermal effect, and drug release of TRUCNS can be successfully achieved under quite moderate eigen temperature $\left(41.6^{\circ} \mathrm{C}\right)$. In consideration of the rather limited heat conduction of nanoparticles at such eigen temperature, the photothermal effect should be well confined to initiate CT only without triggering PTT.

Programmed combination therapy in vitro. To achieve the eigen temperature sensing in the cell, the calibration curve describing the relationship between temperature and UCL was measured in TR-UCNS-labeled MIA PaCa-2 (human pancreatic adenocarcinoma) cells. The curve exhibited a good linear behavior, similar to the one measured in the aqueous solution (Fig. 5a). Then, the $730 \mathrm{~nm}$ laser power densities applied to perform CT and PTT in cells were determined according to the calibration curve. It can be seen that the eigen temperature reached to about $41.5^{\circ} \mathrm{C}$, which was sufficient to initiate the drug release, under $46 \mathrm{~mW} \mathrm{~cm}^{-2} 730 \mathrm{~nm}$ laser irradiation. Moreover, the eigen temperature was elevated to $45.4^{\circ} \mathrm{C}$, which can induce a certain degree of thermal damaging effect, under the power density of $140 \mathrm{~mW} \mathrm{~cm}^{-2}$ (Fig. 5b). Meanwhile, the apparent temperature of the above two sets of laser power were limited within $39^{\circ} \mathrm{C}$ (Fig. 5b). 

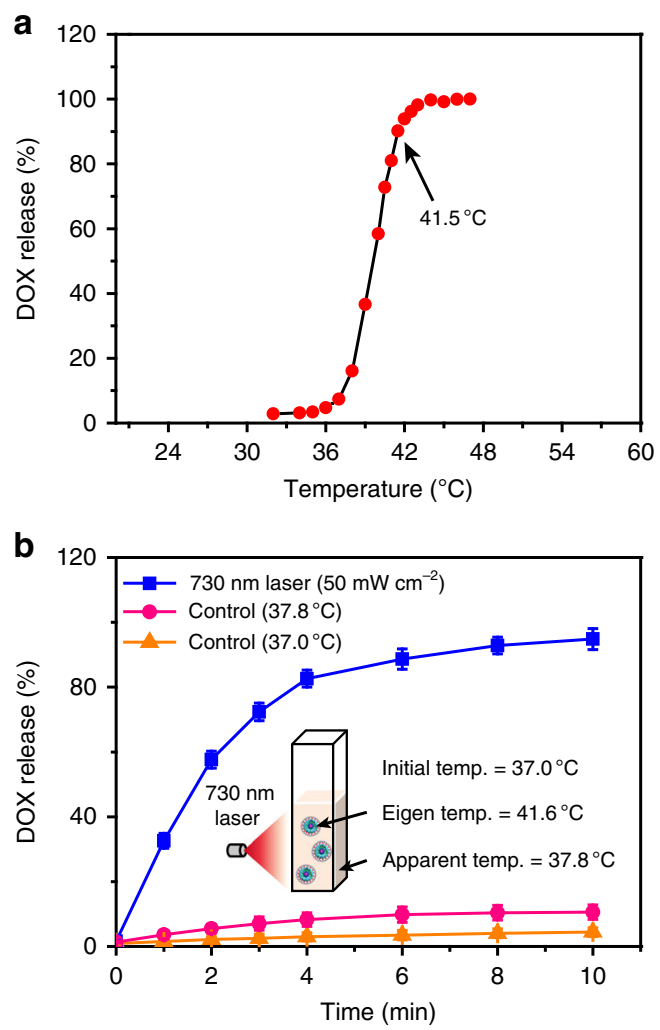

Fig. 4 Drug release behavior of TR-UCNS. a DOX release behavior of TRUCNS aqueous dispersion $\left(0.5 \mathrm{mg} \mathrm{ml}^{-1}\right)$ under external heating. The temperature varied from 32 to $47^{\circ} \mathrm{C}$. The release rate was normalized to $47^{\circ} \mathrm{C}$. It should be noted that the release rate at $41.5^{\circ} \mathrm{C}$ reached to $~ 90 \%$. b DOX release rate of TR-UCNS aqueous dispersion $\left(0.5 \mathrm{mg} \mathrm{ml}^{-1}\right)$ versus time upon $730 \mathrm{~nm}$ laser irradiation $\left(50 \mathrm{~mW} \mathrm{~cm}^{-2}\right)$. Error bars were defined as s.d. $(n=3)$. The eigen temperature and apparent temperature of TRUCNS reached 41.6 and $37.8^{\circ} \mathrm{C}$, respectively. In control experiments, the temperature of the solution was kept at 37 and $37.8^{\circ} \mathrm{C}$, and the release rate was much lower than that achieved by laser irradiation. These results indicate that eigen temperature during photothermal therapy is the key factor for drug release

To confirm the feasibility of separating CT and PTT with the help of eigen temperature, cell viability under different operations were evaluated. MIA PaCa- 2 cells were used throughout the cell experiments. The design of programmed combination therapy is shown in Fig. 6a. MIA PaCa-2 cells were labeled with TR-UCNS and then imported into the process of programmed combination therapy. In this program-like process, the power densities of $730 \mathrm{~nm}$ laser were regulated by the eigen temperature of TR-UCNS to control the photothermal effect. Lower laser power density was used for drug release for chemotherapy (Command 1\#), while the higher one was used for photothermal therapy (Command 2\#). Programmed combination therapy was performed as a sequence of Command 1\# to Command 2\#. Time interval between Command 1 \# to Command 2\# is $4 \mathrm{~h}$, which is determined by the therapeutic efficacy in vitro (Supplementary Figure 8).

TR-UCNS or $730 \mathrm{~nm}$ laser alone did not cause obvious killing effect (Supplementary Figure 7d and e). When the cells incubated with TR-UCNS were irradiated by $730 \mathrm{~nm}$ with low power density $\left(46 \mathrm{~mW} \mathrm{~cm}^{-2}\right)$ to initiate DOX release, a $20 \%$ decrease in viability was observed, compared with the group without irradiation. If the cells were treated in the same condition, but incubated with TR-UCNS in the absence of DOX, only a very slight decrease was presented in cell viability (Fig. 6b). These results indicate that the decrease in cell viability under low power irradiation was mainly attributed to the killing effect of DOX releasing from TR-UCNS, rather than the heat. If the cells were irradiated with high power density $\left(140 \mathrm{~mW} \mathrm{~cm}^{-2}\right)$, which not only initiated drug release for CT, but also gave excessive heat to induce PTT, the cell viability reduced to $51.3 \%$ (Fig. 6b). However, there was still a large portion of cells that survived. Although the enhancement of DOX dose or laser power density may help to eliminate the cells thoroughly (Supplementary Figure $7 \mathrm{~b}$ ), these practices will also bring about damages to normal tissues or even the whole body due to high concentrations of chemodrug and mass heat conduction. To avoid this issue, we controlled the sequence of CT and PTT by modulating the existing two sets of power densities ( 46 and $140 \mathrm{~mW} \mathrm{~cm}^{-2}$, which is represented by 'L' and ' $\mathrm{H}$ ', respectively) to verify whether the scheduling of treatment modes in combination therapy will improve the therapeutic effect. Four groups of cells were all irradiated by $730 \mathrm{~nm}$ laser two times and the irradiation power density of the four groups were $L \rightarrow L, H \rightarrow H, L \rightarrow H$, and $H \rightarrow L$, respectively. Interestingly, nearly all cells were killed (only 1.3\% cells survived) when they were irradiated at $46 \mathrm{~mW} \mathrm{~cm}^{-2}$ first and then at $140 \mathrm{~mW} \mathrm{~cm}^{-2}(\mathrm{~L} \rightarrow \mathrm{H})$ (Fig. 6). Such arrangement of irradiation power could initiate CT first and then PTT. As shown in Fig. $5 c$, when the cells were irradiated under $46 \mathrm{~W} \mathrm{~cm}^{-2}$ for 10 min, eigen temperature mapping images illustrated a relatively small temperature elevation to about $41^{\circ} \mathrm{C}$, and the fluorescence signals of DOX were also detected in the cytoplasm. When the cells were irradiated under $140 \mathrm{~W} \mathrm{~cm}^{-2}$ for $10 \mathrm{~min}$, the eigen temperature raised to $\sim 45^{\circ} \mathrm{C}$ and the cells were dead as their nucleuses could be stained with propidium iodide (PI) (Fig. 5d). Other sets of irradiation power such as $\mathrm{H} \rightarrow \mathrm{H}$ and $\mathrm{H} \rightarrow \mathrm{L}$, which initiated CT and PTT at the same time, and $\mathrm{L} \rightarrow \mathrm{L}$, which initiated CT only, showed limited killing effects (Fig. 6). These results implied that, in CT-PTT combination therapy, the sequence of scheduling CT first, followed by PTT $(\mathrm{L} \rightarrow \mathrm{H})$, had better therapeutic efficacy (about 39 fold enhancement of therapeutic effect) than the conventional operation in which CT and PTT were given simultaneously $(\mathrm{H} \rightarrow \mathrm{L})$. It should be noted that the dosages of DOX in TR-UCNS (the concentration of DOX loaded in TR-UCNS is $2.5 \mu \mathrm{M}$ in the incubation solution) and the heat used in programmed combination therapy were rather low and cannot meet the needs of conventional therapy (Supplementary Figure $7 \mathrm{a}$ and $\mathrm{b}$ ). Furthermore, the sequencing of the treatment modes is realized by monitoring the eigen temperature, which is difficult for conventional strategies that depend on apparent temperature. Previous studies have shown that heat shock protein (HSP) generated from the preliminary thermal treatment will protect the cells from the harm induced by chemodrug ${ }^{64-68}$. To explore the possible reason for the enhancement of the therapeutic effect in programmed combination therapy compared to conventional approaches, we treated the cells with HSP70 activator $(115-7 \mathrm{c})$ first and then evaluated the cell viabilities. It turned out that the cells pre-treated with 115-7c survived in programmed combination therapy and the operations simulating programmed combination therapy with external heating and pure DOX treatment (Supplementary Figure 9). However, the cells without the treatment of $115-7 \mathrm{c}$ were effectively eliminated as expected. Moreover, western bolt analysis was used to detect the HSP expression to give more evidence for the possible mechanism of programmed combination therapy. $\beta$-Actin in the cells was used as internal control and HSP70 was used to represent the HSP. Anti-HSP70 antibody [C92F3A-5] (ab47455, Abcam) was used as primary antibody for HSP70 determination. Anti- $\beta$-Actin antibody (ab8226, Abcam) was used as the primary antibody for $\beta$-Actin determination. The results showed that when cells were treated at $41.5^{\circ} \mathrm{C}$ for $5 \mathrm{~min}$ (the same 

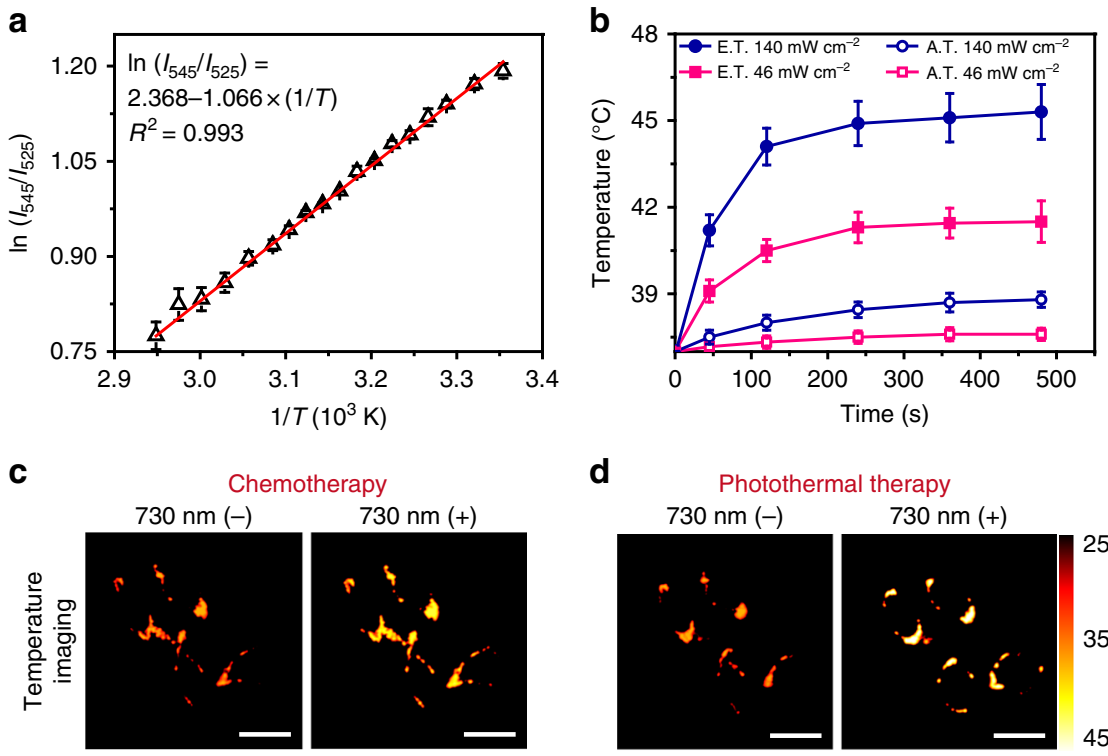

d

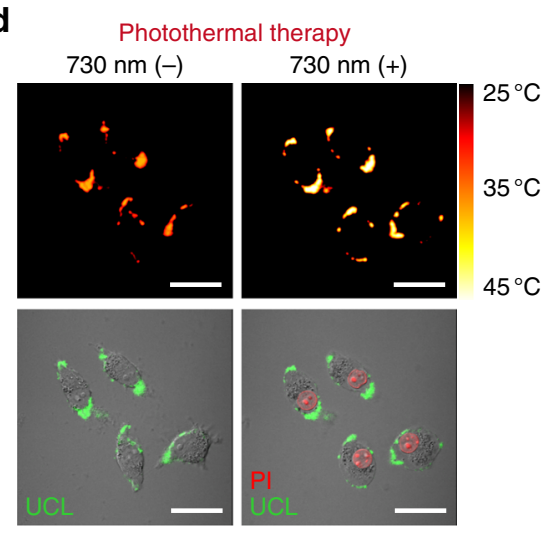

Fig. 5 Eigen temperature sensing and drug release at cell level. a A plot of $\ln \left(I_{525} / I_{545}\right)$ versus $1 / T$ to calibrate the thermometric scale for TR-UCNS in MIA $\mathrm{PaCa}-2$ cells. Average values of $I_{525} / I_{545}$ under different temperatures were given to fit the calibration curve based on three repeated measurements of the UCL spectra. Error bars were defined as s.d. $(n=3)$. b Elevation of A.T. and E.T. of TR-UCNS-labeled cells under irradiation with a $730 \mathrm{~nm}$ laser at 140 and $46 \mathrm{~mW} \mathrm{~cm}^{-2}$. Average values of A.T. and E.T. under different time points were given based on three repeated measurements. Error bars were defined as s. d. $(n=3)$. c Temperature imaging and luminescence imaging (luminescence of TR-UCNS and DOX) of the TR-UCNS-labeled cells for photothermaltriggered chemotherapy with $730 \mathrm{~nm}$ laser irradiation ("730 (-)" and "730 (+)", respectively, indicate the images taken before and after $730 \mathrm{~nm}$ laser irradiation. The power density of $730 \mathrm{~nm}$ laser used for drug release was $46 \mathrm{~mW} \mathrm{~cm}{ }^{-2}$. Temperature mapping of MIA PaCa-2 cells were acquired according to the thermal equilibrium: $\left(I_{545}\right) /\left(I_{525}\right)=C \exp (-\Delta E / k T)$, where $I_{545}$ and $I_{525}$ were the $U C L$ emission intensities in the wavelength region of $535-580 \mathrm{~nm}$ and $515-535 \mathrm{~nm}$, respectively. Scale bars were defined as $30 \mu \mathrm{m}$. d Temperature imaging and luminescence imaging (luminescence of TRUCNS and PI) of the TR-UCNS-labeled cells during photothermal therapy with $730 \mathrm{~nm}$ laser irradiation ("730 (-)" and "730 (+)", respectively, indicate the images taken before and after $730 \mathrm{~nm}$ laser irradiation. The power density of $730 \mathrm{~nm}$ laser used for drug release was $140 \mathrm{~mW} \mathrm{~cm}^{-2}$. Scale bars were defined as $30 \mu \mathrm{m}$

temperature for drug release in the programmed combination therapy by $730 \mathrm{~nm}$ laser at $46 \mathrm{~mW} \mathrm{~cm}^{-2}$ ), their HSP70 level was identical to the cells treated at $37.0^{\circ} \mathrm{C}$ (Supplementary Figure 10a). When the cells were treated at $45.4^{\circ} \mathrm{C}$ for $5 \mathrm{~min}$ (the same temperature for photothermal therapy in the programmed combination therapy by $730 \mathrm{~nm}$ laser at $140 \mathrm{~mW}$ $\mathrm{cm}^{-2}$ ), HSP70 level had a very significant increase (Supplementary Figure 10a). Quantitative data showed that HSP70 level of cells treated at $45.4{ }^{\circ} \mathrm{C}$ was 5.7 -fold higher than cells treated at $41.5^{\circ} \mathrm{C}$ (Supplementary Figure 10b). On the other hand, cells treated at $41.5^{\circ} \mathrm{C}$ only had a very slight increase of HSP70 expression $(\sim 10 \%)$, compared to the cells treated at $37.0^{\circ} \mathrm{C}$ (Supplementary Figure 10b). These results demonstrated that the generation of HSP affects the therapeutic efficacy of chemodrug, so thus the dosages of chemodrug and heat have to be increased to achieve satisfactory killing effect if they were administrated simultaneously. This also explained that programmed combination therapy has better efficacy under low dosage of drug and heat, since the generation of HSP is negligible with such tiny amount of heat during drug release.

Programmed combination therapy in vivo. The excellent treatment effect of the programmed combination therapy by using TR-UCNS prompted us to further carry out the trial of cancer therapy in vivo. TR-UCNS dispersed in $0.9 \% \mathrm{NaCl}$ saline $\left(3 \mathrm{mg} \mathrm{ml}^{-1}, 200 \mu \mathrm{l}\right)$ were administrated to tumor-bearing mice through intravenous injection. Due to the long circulating property of DPPC, TR-UCNS exhibited a tumor-targeting effect, which was demonstrated by the existence of remarkable UCL signals in the tumor region (Supplementary Figure 11a). Ex vivo bioimaging of the injected mice showed that, except the tumor, TR-UCNS also had a distribution in the liver and the spleen (Supplementary Figure 11b). Histological assays based on hematoxylin and eosin (H\&E) staining implied that TR-UCNS had no obvious toxicity in vivo one week after injection (Supplementary Figure 12). In order to determine the laser power densities for drug release and PTT in vivo, UCL signals in the tumor site were collected to decipher the eigen temperature of TR-UCNS. According to the eigen temperature calibration curve measured in a tissue phantom (Fig. 7a), the power densities of $730 \mathrm{~nm}$ laser for drug release and PTT in vivo were adjusted to 57 and $164 \mathrm{~mW} \mathrm{~cm}^{-2}$, as the eigen temperature reached to 41.6 and $45.4{ }^{\circ} \mathrm{C}$ under such two sets of irradiation conditions (Fig. $7 \mathrm{~b}$ ). Then, mice were divided into five groups (five mice in each group) with different treatments. Mice without any treatment were set as blank group. One group of mice were injected with YSUCNP-PdPc@DPPC (without doxorubicin) and were irradiated by $730 \mathrm{~nm}$ laser ( 57 and $164 \mathrm{~mW} \mathrm{~cm}^{-2}, 5 \mathrm{~min}$ for each power density) to be used for administering PTT only. The other 
a

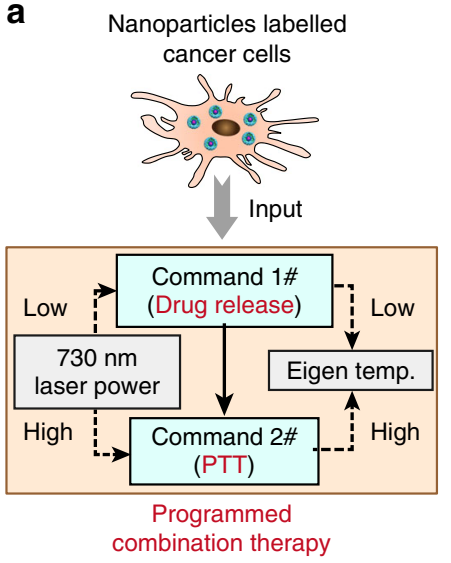

b

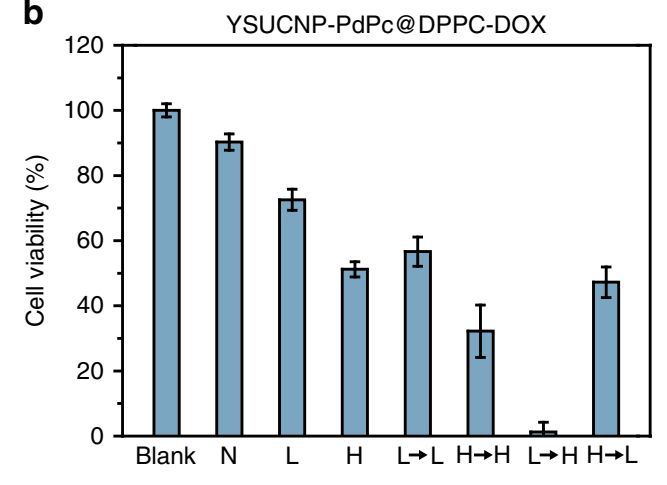

$\mathrm{N}$ : No laser irradiation

L: Low power $730 \mathrm{~nm}$ laser $\left(46 \mathrm{~mW} \mathrm{~cm}^{-2}\right)$

$\mathrm{H}$ : High power $730 \mathrm{~nm}$ laser $\left(140 \mathrm{~mW} \mathrm{~cm}^{-2}\right)$

Fig. 6 Programmed combination therapy at cell level. a Scheme of programmed combination therapy. b Methyl thiazolyl tetrazolium (MTT) assays of YSUCNP-PdPc@DPPC-DOX-labeled MIA PaCa-2 cells. Cells were treated with no laser irradiation $(N), 730 \mathrm{~nm}$ laser irradiation at $46 \mathrm{~mW} \mathrm{~cm}^{-2}(L), 140$ $\mathrm{mW} \mathrm{cm}{ }^{-2}(\mathrm{H})$, and their combinations with different sequences $(\mathrm{L} \rightarrow \mathrm{L}, \mathrm{H} \rightarrow \mathrm{H}, \mathrm{L} \rightarrow \mathrm{H}$ and $\mathrm{H} \rightarrow \mathrm{L})$. Each condition in MTT study is tested 3 times and the average value is given. Error bars were defined as s.d. $(n=3)$
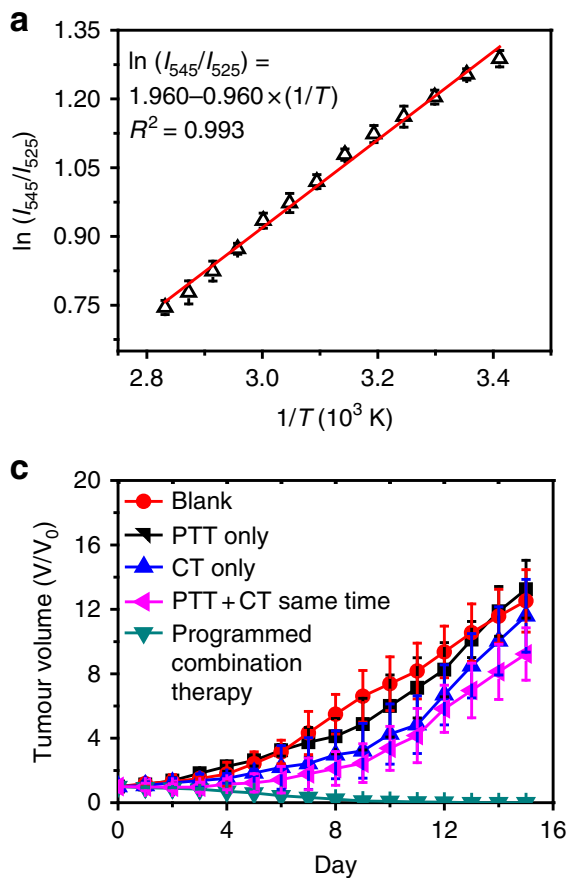

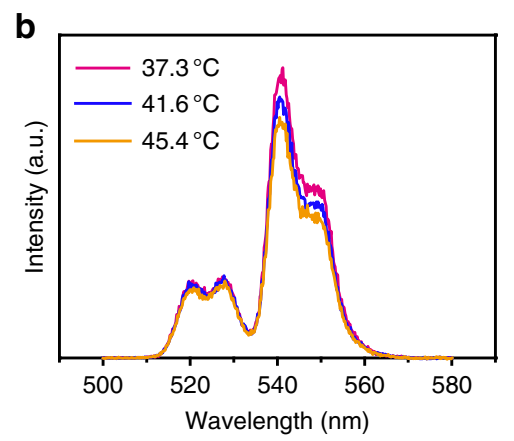

d

(+) YSUCNP-PdPc@DPPC-DOX

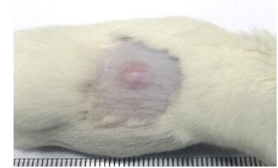

Before treatment

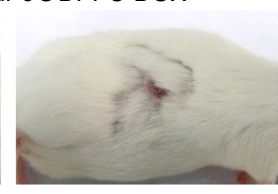

After treatment

Fig. 7 Eigen temperature sensing and programfmed combination therapy in vivo. a A plot of $\ln \left(I_{545} / I_{525}\right)$ versus $1 / T$ to calibrate the thermometric scale for TR-UCNS in the tissue phantom. Each point was measured 3 times and the average values were used. Error bars were defined as s.d. $(n=3)$.

b Upconversion luminescence spectra of TR-UCNS $(500-580 \mathrm{~nm})$ in tumor-bearing mice detected by fiber-optic spectrometer under different $730 \mathrm{~nm}$ laser power density at 0,57 , and $164 \mathrm{~mW} \mathrm{~cm}^{-2}$. Eigen temperature calculated by the upconversion luminescence spectra were $37.3,41.6$, and $45.4{ }^{\circ} \mathrm{C}$. c Growth of tumors in different groups of mice ( $n=5$ in each group) after treatment. The relative tumor volumes were normalized to their initial sizes. Average values of the tumor volume of each group were based on the measurement of the tumors in five mice. Error bars were defined as s.d. $(n=5)$. d Representative photos of tumor-bearing mice with programmed combination therapy

group of mice injected with TR-UCNS and irradiated by $730 \mathrm{~nm}$ laser $\left(57 \mathrm{~mW} \mathrm{~cm}^{-2}, 10 \mathrm{~min}\right.$ ) were used for administering CT only. Another group was injected with TR-UCNS and irradiated by $730 \mathrm{~nm}$ laser $\left(164 \mathrm{~mW} \mathrm{~cm}^{-2}, 10 \mathrm{~min}\right)$ for administering PTT and CT simultaneously, imitating the conventional combination therapy. Finally, another group of mice were irradiated by $730 \mathrm{~nm}$ laser with two sets of power density $\left(57 \mathrm{~mW} \mathrm{~cm}^{-2}\right.$ and then 164 $\mathrm{mW} \mathrm{cm}{ }^{-2}, 5 \mathrm{~min}$ for each power density) to perform the programmed combination therapy. Laser irradiation was performed once a day for a total of 5 days. The tumors in the groups of Blank, PTT only, and CT only grew continuously (Fig. 7c) because the dosage of DOX and heat were rather low. PTT and CT performed simultaneously (conventional combination therapy) showed a limited therapeutic effect in five days and the tumors started to grow gradually in the following days. This is probably because a portion of the cancer cells were killed at the beginning, while the remaining portion of cells survived, and thus the tumors growth was not suppressed later. In the group treated 
with programmed combination therapy, however, the tumors shrunk within 6 days and completely eliminated (Fig. 7c,d, Supplementary Figure 13 and Supplementary Figure 14), and all five mice survived in forty days of the viability test (Supplementary Figure 14). These results indicate that programmed combination therapy can maximize the utility of the two therapeutic modes with low dosages of heat and chemodrug, and consequently, achieve the ideal therapeutic effect where the reoccurrence of tumors is avoided.

\section{Discussion}

In this work, we presented a temperature responsive upconversion nanosystem, $\mathrm{NaLuF}_{4}: 20 \% \mathrm{Yb}, 2 \% \mathrm{Er} @ \mathrm{NaLuF}_{4} @ \mathrm{YS}-\mathrm{SiO}_{2^{-}}$ PdPc@DPPC-DOX (TR-UCNS), which contains both chemodrug and photothermal agent. Under the excitation of near-infrared $730 \mathrm{~nm}$ laser, TR-UCNS can generate photothermal effect and achieve thermal triggered drug release for photothermal therapy and chemotherapy. Due to thermal sensitive nature of the upconversion luminescence generated from TR-UCNS, microscopic temperature of the nanocomposite during photothermal process is determined. By controlling the microscopic temperature, the sequences of chemotherapy and photothermal therapy can be deliberately arranged to achieve programmed combination cancer therapy. When the dosages of chemodrug and heat are kept at low level $(2.5 \mu \mathrm{M}$ of DOX and heat generated by $\sim 150$ $\mathrm{mW} \mathrm{cm} \mathrm{cm}^{-2}$ of $730 \mathrm{~nm}$ laser), programmed combination therapy can achieve 39 folds improvement (Fig. 6b) in therapeutic effect in vitro than conventional combination therapy that initiates chemotherapy and photothermal therapy at the same time. This indicates that programmed combination therapy uses less drug and heat to realize an ideal killing effect that conventional combination therapy may reach by using more drug and heat. It is worth noting that if the same therapeutic effect as programmed combination therapy is wanted, up to 8 folds of DOX is needed $(20 \mu \mathrm{M})$ or up to 2.6 folds of $730 \mathrm{~nm}$ laser power density is needed $\left(400 \mathrm{~mW} \mathrm{~cm}^{-2}\right)$ (Supplementary Figure $7 \mathrm{a}$ and b). Furthermore, the therapeutic effect of programmed combination therapy was also proved in tumor bearing mice. This work provides a non-invasive method to precisely modulate the process of combination therapy which circumvents the interference between the treatment modes and thus maximizes the utility of each treatment mode. Consequently, the applied dosage can be lowered and the therapeutic efficacy is improved at the same time. With the ability to apply such programming methods into other combination therapy strategies, it will allow the medical fraternity to create personalized medical options. The results of this work extend the application of the microscopic temperature modulation and open up a new opportunity for designing next generation of cancer therapy strategies.

\section{Methods \\ Synthesis of $\mathbf{N a L u F}_{\mathbf{4}}: \mathbf{Y b}, \mathbf{E r} @ \mathrm{NaLuF}_{\mathbf{4}}$ (csUCNPs). Typically, $1 \mathrm{mmol} \mathrm{\textrm {LnCl } _ { 3 }}$} ( $\mathrm{Ln}: \mathrm{Lu}, \mathrm{Yb}, \mathrm{Er}$ ) with the molar ratio of 78:20:2 (for the synthesis of $\mathrm{NaLuF}_{4}: \mathrm{Yb}, \mathrm{Er}$ nanoparticles) were added to a $100 \mathrm{~mL}$ three-necked flask containing $6 \mathrm{~mL} \mathrm{OA}$ and $15 \mathrm{~mL}$ ODE. The mixture was heated to $90^{\circ} \mathrm{C}$ for degassing and then heated to 150 ${ }^{\circ} \mathrm{C}$ for 30 min to obtain a transparent solution. The solution was cooled to $50^{\circ} \mathrm{C}$ afterwards and $\mathrm{NH}_{4} \mathrm{~F}(4 \mathrm{mmol})$ and $\mathrm{NaOH}(2.5 \mathrm{mmol})$ dissolved in $5 \mathrm{ml}$ methanol was added into the solution. After degassing for $20 \mathrm{~min}$ at $90^{\circ} \mathrm{C}$, the mixture was heated to $300^{\circ} \mathrm{C}$ as soon as possible and kept at this temperature under argon for 1 $\mathrm{h}$. When the mixture was cooled down to room temperature, the nanoparticles were precipitated by pouring $20 \mathrm{~mL}$ ethanol and cyclohexane (1:1) solution, and collected by centrifugation $(15,900 \times g, 8 \mathrm{~min})$. After washing with ethanol and cyclohexane for three times, hexagonal phase $\mathrm{NaLuF}_{4}: 20 \% \mathrm{Yb}, 2 \% \mathrm{Er}$ nanoparticles were finally redispersed in cyclohexane. $\mathrm{NaLuF}_{4}: \mathrm{Yb}, \mathrm{Er} @ \mathrm{NaLuF}_{4}$ nanoparticles were prepared by epitaxial growth of $\mathrm{NaLuF}_{4}$ layer on $\mathrm{NaLuF}_{4}: \mathrm{Yb}$,Er through a similar procedure. A total of $1.0 \mathrm{mmol} \mathrm{LuCl}_{3}$ was added into a mixed solution of $8 \mathrm{~mL}$ oleic acid (OA) and $12 \mathrm{~mL}$ octadecene (ODE). The mixture was degassed at $90^{\circ} \mathrm{C}$ and then heated to $150^{\circ} \mathrm{C}$ for $30 \mathrm{~min}$ to obtain a transparent solution. After that, 3 $\mathrm{mL}$ ODE containing the as-prepared $\mathrm{NaLuF}_{4}: \mathrm{Yb}, \mathrm{Er}$ nanocrystals was mixed with the solution. The temperature of the mixture was gently raised to $60^{\circ} \mathrm{C}$ to remove cyclohexane. The following procedures were the same as the synthesis of $\mathrm{NaYF}_{4}$ : $\mathrm{Yb}$,Er nanoparticles. The as-obtained $\mathrm{NaLuF}_{4}: \mathrm{Yb}, \mathrm{Er} @ \mathrm{NaLuF}_{4}$ nanoparticles were dispersed in $10 \mathrm{ml}$ cyclohexane for further use.

Synthesis of $\mathbf{N a L u F}_{\mathbf{4}}: \mathbf{Y b}$,Er@NaLuF $\mathbf{4}_{\mathbf{4}} @ \mathbf{Y S}-\mathbf{S i O}_{\mathbf{2}}$ (YSUCNP). Igepal CO-520 (0.5 g) was dissolved in $5 \mathrm{ml}$ cyclohexane to form reaction solution A. csUCNPs (10 $\mathrm{mg}$ ) were dispersed in $5 \mathrm{ml}$ cyclohexane and ultrasonicated for $5 \mathrm{~min}$ to form reaction solution $B$. Then, A and B were mixed together with vigorous stirring. After stirring for $1 \mathrm{~h}, 50 \mu \mathrm{l}$ of ammonia solution (25\%) was added dropwise and the mixture was stirred continuously for another $3 \mathrm{~h}$. After that, $15 \mu \mathrm{l}$ of TEOS was added into the solution on the first day, $30 \mu \mathrm{l}$ of TEOS and $5 \mu \mathrm{l}$ TSD were added on the second day, and then $30 \mu \mathrm{l}$ of TEOS was added on the third day to achieve a multi-layered silica coating. The $10 \mathrm{ml}$ of ethanol was poured into the solution to precipitate the resulting nanoparticles. The products were collected by centrifugation and washed by ethanol 5 times. To make the nanoparticles with a yolkshell-like structure, the as-obtained nanoparticles were dispersed into water/ethanol $(1: 1 \mathrm{v} / \mathrm{v} \%)$ mixed solution and then $1 \mathrm{ml}$ of $1 \%$ HF solution (wt\%) was added and stirred for $6 \mathrm{~h}$ at room temperature. Then, YSUCNP were collected and washed by ethanol 3 times and finally dispersed in ethanol for further use.

Synthesis of YSUCNP-PdPc. To synthesize octabutoxyphthalocyanine palladium (II) (PdPc), $0.1 \mathrm{mmol} \mathrm{1,} \mathrm{4,} \mathrm{8,} \mathrm{11,} \mathrm{15,} \mathrm{18,} \mathrm{22,} \mathrm{25-octabutoxy-29H,31H-phthalocya-}$ nine and $0.3 \mathrm{mmol} \mathrm{PdCl}_{2}$ were added into $5 \mathrm{ml}$ anhydrous dimethylformamide. The mixture was heated to $130^{\circ} \mathrm{C}$ with the protection of $\mathrm{N}_{2}$ for $24 \mathrm{~h}$. When the mixture was cooled down to room temperature, $5 \mathrm{ml}$ methanol was added to precipitate PdPc. The product was washed by $10 \mathrm{ml}$ methanol to remove excessive $\mathrm{PdCl}_{2}$ and then dried for further use. The $20 \mathrm{mg}$ YSUCNP and $2 \mathrm{mg} \mathrm{PdPc}$ were added to $10 \mathrm{ml}$ chloroform. The mixture was ultrasonicated at $30^{\circ} \mathrm{C}$ for $5 \mathrm{~min}$ and then the solvent was removed by a rotary evaporator. After that, $10 \mathrm{ml}$ water was added and YSUCNP-PdPc were redispersed by ultrasonication. The obtained YSUCNP-PdPc was washed with ethanol for one time and water for two times. The adsorbing quantity of the YSUCNP was determined by UV-Vis absorption spectrum. The standard solution of PdPc was prepared and a calibration curve was obtained, and then the supernatant of YSUCNP-PdPc was measured. The photothermal agent $(\mathrm{PdPc})$ loaded on $20 \mathrm{mg}$ YSUCNP is $1.53 \mathrm{mg}(2 \mathrm{mg} \times 76.4 \%$, Supplementary Figure 3d).

Synthesis of YSUCNP-PdPc@DPPC-DOX (TR-UCNS). Firstly, DOX-HCl was neutralized by $\mathrm{NaOH}$ aqueous solution to precipitate hydrophobic DOX. The resulting hydrophobic DOX was dissolved in ethanol to form a solution with a concentration of $2.5 \mathrm{mM}$. Then, $10 \mathrm{mg}$ of DPPC and $50 \mu \mathrm{l}$ of DOX solution were dissolved in $10 \mathrm{ml}$ chloroform. The solvent was removed by a rotary evaporator and formed a homogeneous membrane at the bottom of the bottle. Then, $10 \mathrm{ml}$ aqueous solution of YSUCNP-PdPc $\left(1 \mathrm{mg} \mathrm{ml}^{-1}\right)$ was added and the mixture was ultrasonicated to form YSUCNP-PdPc@DPPC-DOX. The obtained YSUCNPPdPc@DPPC-DOX was separated by centrifugation $(7200 \times g, 8 \mathrm{~min})$ and washed with water for three times. According to the absorption data of DOX in Supplementary Figure $3 \mathrm{e}, 0.115 \mu \mathrm{mol}(2.5 \mathrm{mM} \times 50 \mu \mathrm{l} \times 91.8 \%)$ of DOX molecules are loaded in $10 \mathrm{mg}$ of YSUCNP-PdPc (10 mg YSUCNP-PdPc contain $9.3 \mathrm{mg}$ YSUCNP.). For the convenience of quantification and simple expression in the following experiments, the dosages of TR-UCNS in the solution for temperature detecting, cell incubation, and in vivo administration are represented by the mass concentration of YSUCNP contained in TR-UCNS.

Measurement of eigen temperature of TR-UCNS in the solution. The calibration curve of temperature and upconversion luminescence was obtained in our designed system ${ }^{56}$. TR-UCNS aqueous dispersion $\left(2 \mathrm{ml}, 0.5 \mathrm{mg} \mathrm{ml}^{-1}\right.$, mass concentration here is represented by YSUCNP in TR-UCNS) in a quartz cuvette was put in Edinburgh FLS-920 fluorescence spectrometer with a temperature adjustable holder. The solution was controlled at different temperatures from 10 to $90^{\circ} \mathrm{C}$, and the upconversion luminescence from 500 to $580 \mathrm{~nm}$ at each temperature point was collected under the excitation of a continuous wave $(\mathrm{CW})$ $980 \mathrm{~nm}$ laser $\left(50 \mathrm{~mW} \mathrm{~cm}^{-2}\right)$. The intensity ratio of the UCL centered at 525 and $545 \mathrm{~nm}$ at each temperature point was substituted in Eq. 1 to get the calibration curve. Then, the solution was irradiated by $730 \mathrm{~nm}$ laser at different power density. UCL spectra of TR-UCNS were collected under $980 \mathrm{~nm}$ laser excitation to calculate the eigen temperature, and the apparent temperature was detected by a thermocouple.

Observation of DOX release in TR-UCNS. The release behavior of DOX in TRUCNS was observed by recording the fluorescence of DOX under $488 \mathrm{~nm}$ light excitation. Aqueous dispersion containing TR-UCNS $\left(2 \mathrm{ml}, 0.5 \mathrm{mg} \mathrm{ml}^{-1}\right.$, mass concentration here is represented by YSUCNP in TR-UCNS) was placed in Edinburgh FLS-920 fluorescence spectrometer. The solution was heated to different temperatures from 32 to $48^{\circ} \mathrm{C}$ to figure out the temperature threshold $\left(41.6^{\circ} \mathrm{C}\right)$ for the drug release. On the other hand, another solution was irradiated by $730 \mathrm{~nm}$ laser to investigate the release behavior under photothermal effect. Eigen temperature of TR-UCNS was set at $\sim 41.6^{\circ} \mathrm{C}$ by controlling the laser power density at 
$50 \mathrm{~mW} \mathrm{~cm}{ }^{-2}$. The corresponding apparent temperature was $37.8^{\circ} \mathrm{C}$. The release behavior at 37.8 and $37^{\circ} \mathrm{C}$ was also observed. Fluorescence spectra of DOX excited by $488 \mathrm{~nm}$ light of xenon lamp were collected at each time point to calculate the release rate.

Cell culture and confocal upconversion imaging. MIA PaCa-2 cells were provided by the Institute of Biochemistry and Cell Biology, SIBS, CAS (China). MIA $\mathrm{PaCa}-2$ cell line used in this work is not included in the list of misidentified cell lines made by International Cell Line Authentication Committee (ICLAC) and is tested without mycoplasma contamination. Cells $\left(1 \times 10^{8} 1^{-1}\right)$ were plated on culture dish incubated with DMEM (Dulbecco's Modified Eagle Medium) supplemented by $10 \%$ fetal bovine serum at $37^{\circ} \mathrm{C}$ and $5 \% \mathrm{CO}_{2}$ for $24 \mathrm{~h}$. Then, the cells were washed with phosphate buffer and $2 \mathrm{ml}$ of a serum-free medium containing $200 \mathrm{\mu g} \mathrm{ml}^{-1}$ (mass concentration is represented by YSUCNP in TR-UCNS. Dosage of DOX and PdPc contained are $2.5 \mu \mathrm{M}$ and $15.3 \mu \mathrm{g} \mathrm{ml}^{-1}$, respectively.) TR-UCNS was added into the dish for further incubation at $37^{\circ} \mathrm{C}$ and $5 \% \mathrm{CO}_{2}$ for $2 \mathrm{~h}$. After that, the cells were washed with phosphate buffer three times to perform confocal microscopy imaging. Confocal upconversion imaging was accomplished on the laser scanning UCL microscope with an Olympus FV1000 scanning unit, which is designed by our group ${ }^{69}$. UCL signals were excited by a CW laser at $980 \mathrm{~nm}$ with a focused power of $19 \mathrm{~mW}$. The UCL signals at $500-580 \mathrm{~nm}$ were collected under a $60 \times$ oil-immersion objective lens. To observe the release of DOX and therapeutic efficacy, cells were irradiated by a $730 \mathrm{~nm}$ laser at $46 \mathrm{~mW} \mathrm{~cm}^{-2}$ first and then at $140 \mathrm{~mW} \mathrm{~cm}^{-2}$. The irradiation time under each power density was $5 \mathrm{~min}$. Propidium iodide (PI) was used to identify whether the cells were dead after each time of irradiation. Fluorescence signals of DOX were collected at 550-610 nm under 488 $\mathrm{nm}$ excitation. PI signals were collected at $650-700 \mathrm{~nm}$ under $532 \mathrm{~nm}$ excitation.

Evaluation of cell viability. Cell viability was quantitatively evaluated by methyl thiazolyl tetrazolium (MTT) assays. Briefly, the cells were planted into a 96-well cell culture plate at $5 \times 10^{4}$ per well and were cultured at $37^{\circ} \mathrm{C}$ and $5 \% \mathrm{CO}_{2}$ for $24 \mathrm{~h}$. After that, the cells were treated with different conditions (including the incubation of DOX, TR-UCNS at different concentration, and laser irradiations under different power densities) and further cultured at $37^{\circ} \mathrm{C}$ and $5 \% \mathrm{CO}_{2}$ for another $24 \mathrm{~h}$. Then, MTT $\left(5 \mu \mathrm{l}, 5 \mathrm{mg} \mathrm{ml}^{-1}\right)$ was added to each well and the cells were incubated at $37{ }^{\circ} \mathrm{C}$ and $5 \% \mathrm{CO}_{2}$ for additional $4 \mathrm{~h}$. A total of $50 \mu \mathrm{l}$ of $10 \%$ SDS was added in each well and the plate was held at room temperature for $12 \mathrm{~h}$. The optical density $\mathrm{OD}_{570}$ value (Abs.) of each well, with background subtraction at $690 \mathrm{~nm}$, was detected by a Tecan Infinite M200 monochromator-based multifunction microplate reader. Cell viability (\%) was calculated using Eq. 2, which is given below:

$$
\text { Cell viability }(\%)=\left(\frac{\text { Mean of Abs. value of treatment group }}{\text { Mean Abs. value of control }}\right) 100 \%
$$

HSP70 expression analysis. Western blot analysis was used to determine the expression of HSP70 in MIA PaCa-2 cells. Two groups of cells were treated at 41.5 or $45.4^{\circ} \mathrm{C}$ for $5 \mathrm{~min}$, which simulate the drug release and photothermal process in programmed combination therapy. The other set of cells was treated at $37.0^{\circ} \mathrm{C}$ as control. For western blot experiment, an equal amount of total protein was added in each well for electrophoresis. The separated protein was transferred into polyvinylidene difluoride membrane from the gel. $\beta$-Actin in the cells was used as internal control and HSP70 was used to represent the heat shock protein. AntiHSP70 antibody [C92F3A-5] (ab47455, Abcam) was used as primary antibody for HSP70 determination. Anti- $\beta$-Actin antibody (ab8226, Abcam) was used as primary antibody for $\beta$-Actin determination. The ratio of primary antibodies for $\beta$ Actin and HSP70 is 1:1000 and the ratio of secondary antibodies is 1:10,000. The protein bands were scanned digitally for data representation and quantitative analysis. For quantitative analysis, each group of samples $\left(37.0,41.5\right.$, and $\left.45.4^{\circ} \mathrm{C}\right)$ was in triplicate.

Eigen temperature mapping of TR-UCNS-labeled cells. Temperature calibration curve for cell was measured in laser scanning UCL microscope with an Olympus FV1000 scanning unit and the temperature was adjusted with help of an external heating platform. UCL signals at $540-570 \mathrm{~nm}\left(I_{545}\right)$ and $515-535 \mathrm{~nm}\left(I_{525}\right)$ were collected, respectively, at certain temperature to determine the ratio. Cells incubated with TR-UCNS were irradiated by $730 \mathrm{~nm}$ laser at $46 \mathrm{~mW} \mathrm{~cm}^{-2}$ or $140 \mathrm{~mW}$ $\mathrm{cm}^{-2}$ for $5 \mathrm{~min}$. The corresponding UCL images at $540-570 \mathrm{~nm}$ and $515-535 \mathrm{~nm}$ during $730 \mathrm{~nm}$ laser irradiation were collected and manipulated mathematically based on the calibration formula to obtain the image of the eigen temperature.

Tumor xenografts. Animal procedures were in accordance with the guidelines of the Institutional Animal Care and Use Committee (IACUC), School of Pharmacy, Fudan University. MIA PaCa-2 cells were harvested by incubation with $0.05 \%$ trypsin-EDTA and then collected by centrifugation and resuspended in sterile phosphate buffer saline. Cells $\left(10^{8}\right.$ cells per mouse) were subcutaneously implanted into four-week-old male Balb/c scid mice. Tumor-bearing mice were ready for bioimaging, and programmed combination therapy was performed when the tumors reached an average diameter of $0.5 \mathrm{~cm}$.
Upconversion bioimaging in vivo. Whole-body bioimaging was accomplished by the in vivo imaging system designed by our group ${ }^{70}$. A $0-5 \mathrm{~W}$ adjustable continuous wave $980 \mathrm{~nm}$ laser was used as excitation and Andor DU897 EMCCD was used as a signal collector. A $720 \mathrm{~nm}$ short-pass filter was used to exclude the excitation light. Tumor-bearing mice were injected with $0.9 \% \mathrm{NaCl}$ saline containing TR-UCNS $\left(3 \mathrm{mg} \mathrm{ml}^{-1}, 200 \mu \mathrm{l}\right)$ through the tail vein. UCL was performed 6 $\mathrm{h}$ after injection of TR-UCNS.

Detection of eigen temperature in vivo. The temperature calibration curve for living body was obtained in tissue phantom of which the synthetic method is reported elsewhere. A $2 \mathrm{~cm}^{3}$ tissue phantom containing TR-UCNS $\left(0.5 \mathrm{mg} \mathrm{cm}^{-3}\right.$, represented by the mass concentration of YSUCNP contained in TR-UCNS) was put in quartz cuvette and heated to a series of temperature from $10-90^{\circ} \mathrm{C}$. UCL spectra at each temperature point were recorded by Edinburgh FLS-920 fluorescence spectrometer. To observe the eigen temperature during photothermal process, tissue phantom was irradiated by a $730 \mathrm{~nm}$ laser, and the corresponding UCL spectra were collected to calculate the eigen temperature, according to the calibration curve. As to the eigen temperature monitoring in tumor-bearing mice, a fiber-optic spectrometer (PG2000 Pro, Ideaoptics, China) was used to collect the UCL signals at the tumor site under excitation of $980 \mathrm{~nm}$ laser. The $730 \mathrm{~nm}$ laser power densities for drug release and photothermal therapy were determined according to the eigen temperature measured in vivo.

Programmed combination therapy in vivo. For programmed combination therapy, mice injected with TR-UCNS were irradiated by the $730 \mathrm{~nm}$ laser with a light spot of $\sim 10 \mathrm{~mm}$ diameter and was focused on the tumor area. Mice were first irradiated at the power density of $57 \mathrm{~mW} \mathrm{~cm}^{-2}$ for $5 \mathrm{~min}$ and then irradiated at $164 \mathrm{~mW} \mathrm{~cm}^{-2}$ for another $5 \mathrm{~min}$ after $4 \mathrm{~h}$ from the first time of irradiation. The control groups were irradiated at $57 \mathrm{~mW} \mathrm{~cm}^{-2}$ for $10 \mathrm{~min}$ or at $164 \mathrm{~mW} \mathrm{~cm}^{-2}$ for $10 \mathrm{~min}$. The blank group was not irradiated at $730 \mathrm{~nm}$ laser. Tumor sizes of each group were measured every day after treatment. Each group contained five mice. The tumor sizes were measured using a caliper and calculated as volume $=$ (tumor length) $\times(\text { tumor width })^{2} / 2$. Relative tumor volumes were normalized and were calculated as $V / V_{0}\left(V_{0}\right.$ is the tumor volume when the treatment was initiated) and average values were used. Error bars were defined as s.d. No blinding or randomization was used in animal studies. According to the guidelines of Institutional Animal Care and Use Committee (IACUC), School of Pharmacy, Fudan University, the maximum permitted tumor size is $20 \mathrm{~mm}$ in an average diameter for mice. The tumors' size in this work are confined within this criterion.

Other information. The source of all law materials, details of characterization, and calculation of the photothermal conversion efficiency are presented in the Supplementary Methods section in Supplementary Information file.

Data availability. The authors declare that all the data supporting the findings of this study are presented in the article and its Supplementary Information files. All relevant data are also available from the corresponding author upon request.

Received: 23 November 2017 Accepted: 3 May 2018

Published online: 05 June 2018

\section{References}

1. Al-Lazikani, B., Banerji, U. \& Workman, P. Combinatorial drug therapy for cancer in the post-genomic era. Nat. Biotechnol. 30, 679-692 (2012).

2. Peer, D. et al. Nanocarriers as an emerging platform for cancer therapy. Nat. Nanotechnol. 2, 751-760 (2007).

3. Davis, M. E., Chen, Z. \& Shin, D. M. Nanoparticle therapeutics: an emerging treatment modality for cancer. Nat. Rev. Drug. Discov. 7, 771-782 (2008).

4. Sykes, E. A. et al. Tailoring nanoparticle designs to target cancer based on tumor pathophysiology. Proc. . Natl. Acad. Sci. USA. 113, E1142-E1151 (2016).

5. Mercado-Lubo, R. et al. A Salmonella nanoparticle mimic overcomes multidrug resistance in tumours. Nat. Commun. 7, 12225 (2016).

6. Zhang, C. et al. Magnesium silicide nanoparticles as a deoxygenation agent for cancer starvation therapy. Nat. Nanotechnol. 12, 378-386 (2017).

7. Parhi, P., Mohanty, C. \& Sahoo, S. K. Nanotechnology-based combinational drug delivery: an emerging approach for cancer therapy. Drug Discov. Today 17, 1044-1052 (2012)

8. Xu, X., Ho, W., Zhang, X., Bertrand, N. \& Farokhzad, O. Cancer nanomedicine: from targeted delivery to combination therapy. Trends Mol. Med. 21, 223-232 (2015).

9. Hu, C.-M. J. \& Zhang, L. Nanoparticle-based combination therapy toward overcoming drug resistance in cancer. Biochem. Pharmacol. 83, 1104-1111 (2012). 
10. Tao, Y. et al. Engineered, self-assembled near-infrared photothermal agents for combined tumor immunotherapy and chemo-photothermal therapy. Biomaterials 35, 6646-6656 (2014).

11. Song, J. B., Huang, P., Duan, H. W. \& Chen, X. Y. Plasmonic vesicles of amphiphilic nanocrystals: optically active multifunctional platform for cancer diagnosis and therapy. Acc. Chem. Res. 48, 2506-2515 (2015)

12. Ma, L., Kohli, M. \& Smith, A. Nanoparticles for combination drug therapy. ACS Nano 7, 9518-9525 (2013).

13. Brigger, I., Dubernet, C. \& Couvreur, P. Nanoparticles in cancer therapy and diagnosis. Adv. Drug Deliv. Rev. 54, 631-651 (2002).

14. McCarthy, J. R. \& Weissleder, R. Multifunctional magnetic nanoparticles for targeted imaging and therapy. Adv. Drug Deliv. Rev. 60, 1241-1251 (2008).

15. Zhao, L. et al. Near-infrared photoregulated drug release in living tumor tissue via yolk-shell upconversion nanocages. Adv. Funct. Mater. 24, 363-371 (2014).

16. Chen, Q. et al. Intelligent albumin- $\mathrm{MnO}_{2}$ nanoparticles as $\mathrm{pH}-/ \mathrm{H}_{2} \mathrm{O}_{2}$ responsive dissociable nanocarriers to modulate tumor hypoxia for effective combination therapy. Adv. Mater. 28, 7129-7136 (2016).

17. Zhang, Z. et al. Mesoporous silica-coated gold nanorods as a light-mediated multifunctional theranostic platform for cancer treatment. Adv. Mater. 24, $1418-1423$ (2012).

18. Lv, R. et al. An imaging-guided platform for synergistic photodynamic/ photothermal/chemo-therapy with $\mathrm{pH} /$ temperature-responsive drug release. Biomaterials 63, 115-127 (2015).

19. He, F. et al. Enhanced up/down-conversion luminescence and heat: simultaneously achieving in one single core-shell structure for multimodal imaging guided therapy. Biomaterials 105, 77-88 (2016).

20. Liu, H. et al. Multifunctional gold nanoshells on silica nanorattles: a platform for the combination of photothermal therapy and chemotherapy with low systemic toxicity. Angew. Chem. Int. Ed. 50, 891-895 (2011).

21. Park, J.-H. et al. Cooperative nanoparticles for tumor detection and photothermally triggered drug delivery. Adv. Mater. 22, 880-885 (2010).

22. Liu, T. et al. Drug delivery with PEGylated $\mathrm{MoS}_{2}$ nano-sheets for combined photothermal and chemotherapy of cancer. Adv. Mater. 26, 3433-3440 (2014).

23. Hauck, T. S., Jennings, T. L., Yatsenko, T., Kumaradas, J. C. \& Chan, W. C. W. Enhancing the toxicity of cancer chemotherapeutics with gold nanorod hyperthermia. Adv. Mater. 20, 3832-3838 (2008).

24. Cai, X. et al. A versatile nanotheranostic agent for efficient dual-mode imaging guided synergistic chemo-thermal tumor therapy. Adv. Funct. Mater. 25, 2520-2529 (2015)

25. Sun, X., Wang, C., Gao, M., Hu, A. \& Liu, Z. Remotely controlled red blood cell carriers for cancer targeting and near-infrared light-triggered drug release in combined photothermal-chemotherapy. Adv. Funct. Mater. 25, 2386-2394 (2015).

26. Dong, K., Liu, Z., Li, Z., Ren, J. \& Qu, X. Hydrophobic anticancer drug delivery by a $980 \mathrm{~nm}$ laser-driven photothermal vehicle for efficient synergistic therapy of cancer cells in vivo. Adv. Mater. 25, 4452-4458 (2013).

27. Zhang, L. et al. Tailored synthesis of octopus-type janus nanoparticles for synergistic actively-targeted and chemo-photothermal therapy. Angew. Chem. Int. Ed. 128, 2158-2161 (2016)

28. Sershen, S. R., Westcott, S. L., Halas, N. J. \& West, J. L. Temperature-sensitive polymer-nanoshell composites for photothermally modulated drug delivery. J. Biomed. Mater. Res. 51, 293-298 (2000).

29. Wondergem, J. et al. Effect of adriamycin combined with whole body hyperthermia on tumor and normal tissues. Cancer Res. 51, 3559-3567 (1991).

30. Kusumoto, T. et al. Sequence dependence of the hyperthermic potentiation of carboplatin-induced cytotoxicity and intracellular platinum accumulation in HeLa cells. Br. J. Cancer 68, 259 (1993).

31. Bull, J., Strebel, F., Jenkins, G., Deng, W. \& Rowe, R. The importance of schedule in whole body thermochemotherapy. Int. J. Hyperth. 24, 171-181 (2008).

32. Hahn, G. M. \& Strande, D. P. Cytotoxic effects of hyperthermia and adriamycin on Chinese hamster cells. J. Natl Cancer Inst. 57, 1063-1067 (1976).

33. You, J. et al. Photothermal-chemotherapy with doxorubicin-loaded hollow gold nanospheres: a platform for near-infrared light-trigged drug release. $J$. Control Release 158, 319-328 (2012).

34. Baba, H., Maehara, Y., Takeuchi, H., Inutsuka, S. \& Sugimachi, K. Optimal scheduling increases therapeutic gain of adriamycin combined with hyperthermia. Anticancer Res. 13, 651-654 (1992).

35. Freddi, S. et al. A molecular thermometer for nanoparticles for optical hyperthermia. Nano. Lett. 13, 2004-2010 (2013).

36. Kucsko, G. et al. Nanometre-scale thermometry in a living cell. Nature 500, 54-58 (2013)
37. Loew, P., Kim, B., Takama, N. \& Bergaud, C. High-spatial-resolution surfacetemperature mapping using fluorescent thermometry. Small 4, 908-914 (2008).

38. Wang, X.-D., Wolfbeis, O. S. \& Meier, R. J. Luminescent probes and sensors for temperature. Chem. Soc. Rev. 42, 7834-7869 (2013).

39. Shang, L., Stockmar, F., Azadfar, N. \& Nienhaus, G. U. Intracellular thermometry by using fluorescent gold nanoclusters. Angew. Chem., Int. Ed. 52, 11154-11157 (2013).

40. Okabe, K. et al. Intracellular temperature mapping with a fluorescent polymeric thermometer and fluorescence lifetime imaging microscopy. Nat. Commun. 3, 705 (2012)

41. Rocha, U. et al. Subtissue thermal sensing based on neodymium-doped $\mathrm{LaF}_{3}$ nanoparticles. ACS Nano 7, 1188-1199 (2013).

42. Bünzli, J.-C. G. Lanthanide light for biology and medical diagnosis. J. Lumin 170, 866-878 (2016).

43. $\mathrm{Lu}, \mathrm{S}$. et al. Multifunctional nano-bioprobes based on rattle-structured upconverting luminescent nanoparticles. Angew. Chem. Int. Ed. 54, 7915-7919 (2015).

44. Chen, G., Ågren, H., Ohulchanskyy, T. Y. \& Prasad, P. N. Light upconverting core-shell nanostructures: nanophotonic control for emerging applications. Chem. Soc. Rev. 44, 1680-1713 (2015).

45. Vetrone, F. et al. Temperature sensing using fluorescent nanothermometers. ACS Nano 4, 3254-3258 (2010).

46. Sedlmeier, A., Achatz, D. E., Fischer, L. H., Gorris, H. H. \& Wolfbeis, O. S. Photon upconverting nanoparticles for luminescent sensing of temperature. Nanoscale 4, 7090-7096 (2012).

47. Dong, H., Sun, L.-D. \& Yan, C.-H. Energy transfer in lanthanide upconversion studies for extended optical applications. Chem. Soc. Rev. 44, 1608-1634 (2015).

48. Gnach, A., Lipinski, T., Bednarkiewicz, A., Rybka, J. \& Capobianco, J. A. Upconverting nanoparticles: assessing the toxicity. Chem. Soc. Rev. 44, 1561-1584 (2015).

49. Wei, W. et al. Alleviating luminescence concentration quenching in upconversion nanoparticles through organic dye sensitization. J. Am. Chem. Soc. 138, 15130-15133 (2016).

50. $\mathrm{Wu}, \mathrm{X}$. et al. Dye-sensitized core/active shell upconversion nanoparticles for optogenetics and bioimaging applications. ACS Nano 10, 1060-1066 (2016).

51. Zhou, B., Shi, B., Jin, D. \& Liu, X. Controlling upconversion nanocrystals for emerging applications. Nat. Nanotechnol. 10, 924-936 (2015).

52. Brites, C. D. et al. Instantaneous ballistic velocity of suspended Brownian nanocrystals measured by upconversion nanothermometry. Nat. Nanotechnol. 11, 851-856 (2016).

53. Shao, W. et al. Tunable narrow band emissions from dye-sensitized core/shell/ shell nanocrystals in the second near-infrared biological window. J. Am. Chem. Soc. 138, 16192-16195 (2016).

54. Wang, X. et al. Dye-sensitized lanthanide-doped upconversion nanoparticles. Chem. Soc. Rev. 46, 4150-4167 (2017).

55. Bünzli, J.-C. G. Rising stars in science and technology: luminescent lanthanide materials. Eur. J. Inorg. Chem. 2017, 5058-5063 (2017).

56. Zhu, X. J. et al. Temperature-feedback upconversion nanocomposite for accurate photothermal therapy at facile temperature. Nat. Commun. 7, 10437 (2016).

57. Li, Z. Q. \& Zhang, Y. An efficient and user-friendly method for the synthesis of hexagonal-phase $\mathrm{NaYF}_{4}: \mathrm{Yb}, \mathrm{Er} / \mathrm{Tm}$ nanocrystals with controllable shape and upconversion fluorescence. Nanotechnology 19, 345606 (2008).

58. Yao, L., Shen, B., Cao, C., Feng, W. \& Li, F. Chemodosimeter functionalized magnetic silica yolk-shell nanocomposite for sensing and removal of $\mathrm{Hg}^{2+}$. RSC Adv. 4, 20252-20255 (2014).

59. Chen, D., Li, L. L., Tang, F. Q. \& Qi, S. O. Facile and scalable synthesis of tailored silica "nanorattle" structures. Adv. Mater. 21, 3804-3807 (2009).

60. Mills, J. K. \& Needham, D. 6-The materials engineering of temperaturesensitive liposomes. Methods Enzymol. 387, 82-113 (2004).

61. Lu, T. \& ten Hagen, T. L. M. Inhomogeneous crystal grain formation in DPPC-DSPC based thermosensitive liposomes determines content release kinetics. J. Control Release 247, 64-72 (2017).

62. Qiu, F. et al. Artificial bacterial flagella functionalized with temperaturesensitive liposomes for controlled release. Sens. Actuat. B. Chem. 196, 676-681 (2014).

63. Meng, $\mathrm{H}$. et al. Use of a lipid-coated mesoporous silica nanoparticle platform for synergistic gemcitabine and paclitaxel delivery to human pancreatic cancer in mice. ACS Nano 9, 3540-3557 (2015).

64. Pelz, J. O. W. et al. Hyperthermic intraperitoneal chemotherapy in patients with peritoneal carcinomatosis: role of heat shock proteins and dissecting effects of hyperthermia. Ann. Surg. Oncol. 20, 1105-1113 (2013).

65. Ciocca, D. R. et al. Response of human breast cancer cells to heat shock and chemotherapeutic drugs. Cancer Res. 52, 3648-3654 (1992).

66. Engelhardt, R. In Hyperthermia and the Therapy of Malignant Tumors (ed. Streffer, C.) 136-203 (Springer, Berlin, 1987). 
67. Donaldson, S., Gordon, L. \& Hahn, G. Protective effect of hyperthermia against the cytotoxicity of actinomycin D on Chinese hamster cells. Cancer Treat. Rep. 62, 1489-1495 (1978).

68. Wallner, K. \& Li, G. C. Adriamycin resistance, heat resistance and radiation response in Chinese hamster fibroblasts. Int. J. Radiat. Oncol. Biol. Phys. 12, 829-833 (1986).

69. $\mathrm{Yu}, \mathrm{M}$. et al. Laser scanning up-conversion luminescence microscopy for imaging cells labeled with rare-earth nanophosphors. Anal. Chem. 81, 930-935 (2009).

70. Xiong, L. et al. High contrast upconversion luminescence targeted imaging in vivo using peptide-labeled nanophosphors. Anal. Chem. 81, 8687-8694 (2009).

\section{Acknowledgements}

We thank the National Natural Science Foundation of China (21527801, 21231004, and 21722101), the National Key R\&D Program of China (Grant 2017YFA0205100), the National Basic Research Program of China (2015CB931800), and Shanghai Sci. Tech. Comm. (15QA1400700) for financial support. We also thank Dr. Jianfeng Li for the discussion and valuable suggestions on this work.

\section{Author contributions}

The manuscript was written through the contributions of all the authors. All authors have given approval to the final version of the manuscript. X.Z., J.L., X.Q., and Y.L. performed the experiments. X.Z., W.F., and F.L. analyzed the data, wrote the manuscript, and designed the experimental approach

\section{Additional information}

Supplementary Information accompanies this paper at https://doi.org/10.1038/s41467018-04571-4.

Competing interests: The authors declare no competing interests.

Reprints and permission information is available online at http://npg.nature.com/ reprintsandpermissions/

Publisher's note: Springer Nature remains neutral with regard to jurisdictional claims in published maps and institutional affiliations.

(c) (i) Open Access This article is licensed under a Creative Commons Attribution 4.0 International License, which permits use, sharing, adaptation, distribution and reproduction in any medium or format, as long as you give appropriate credit to the original author(s) and the source, provide a link to the Creative Commons license, and indicate if changes were made. The images or other third party material in this article are included in the article's Creative Commons license, unless indicated otherwise in a credit line to the material. If material is not included in the article's Creative Commons license and your intended use is not permitted by statutory regulation or exceeds the permitted use, you will need to obtain permission directly from the copyright holder. To view a copy of this license, visit http://creativecommons.org/ licenses/by/4.0/.

(C) The Author(s) 2018 